\title{
Performance of Palm Oil Fuel Ash and Rice Husk Ash Based Geopolymer Mortar
}

\author{
Dhabit Zahin Alias Tudin ${ }^{1 *}$, Ahmad Nurfaidhi Rizalman ${ }^{1}$, and Hidayati Asrah ${ }^{1}$ \\ ${ }^{1}$ Faculty of Engineering, Universiti Malaysia Sabah, Jalan UMS, 88400 Kota Kinabalu, Sabah, \\ Malaysia
}

\begin{abstract}
Geopolymer is a cement free material which uses binder produced by the reaction of the alkaline liquid solution with binding agents. In this study, the performance of geopolymer mortar using Palm Oil Fuel Ash (POFA) and Rice Husk Ash (RHA) as binding agents was carried out. The tests conducted in this research were Specific Gravity, XRay Diffraction (XRD), Scanning Electron Microscope (SEM), bulk density and compressive strength at $7^{\text {th }}, 14^{\text {th }}$ and $28^{\text {th }}$ days. The results show both POFA and RHA materials fulfilled the criteria as a pozzolanic material. Meanwhile, the cement based mortar has the highest bulk density, followed by POFA based and RHA based geopolymer mortar. The cement based mortar was also identified to have the highest compressive strength due to its densest structure. However, it was found that the RHA based geopolymer mortar has higher compressive strength than the POFA based geopolymer despite its lower density. This is due to the high silica content in RHA which promote more silica-oxygen-silica bonds than POFA.
\end{abstract}

\section{Introduction}

Geopolymer concrete was introduced by Joseph Davidovits in 1978 [1] in response to the global warming impact due to the production of cement [2]. The term geopolymer represents the binders obtained from the chemical reaction called as geo-polymerisation. The geo-polymerisation involves the activation of silicon ( $\mathrm{Si}$ ) and aluminum (Al) with an alkaline liquid solution such as Sodium Hydroxide $(\mathrm{NaOH})$ and Sodium Silicate $\left(\mathrm{Na}_{2} \mathrm{SiO}_{3}\right)$ [3]. Due to the high content of silicon and aluminum in the binder, the cement in concrete can be replaced hence reduces the demand for cement production.

In geopolymer concrete, industrial wastes such as Palm Oil Fuel Ash (POFA), Rice Husk Ash (RHA), Fly Ash (FA), and Ground Granulated Blast Furnace Slag (GGBS) are used as binding agents to replace cement. Since the production of geopolymer concrete is totally cemented free, the $\mathrm{CO}_{2}$ emission is lower thus creating environment-friendly green concrete. Another advantage of geopolymer concrete is it increases the strength, ductility, and durability compared to the Ordinary Portland Cement (OPC) $[4,5]$. This is due to the geo-polymerisation reaction that occurs between silica and alumina molecules which contribute to the higher strength in the geopolymer concrete compared to the normal concrete [6].

\footnotetext{
${ }^{*}$ Corresponding author: dhabitzahin@gmail.com
} 
The main aim of this research is to investigate the performance of POFA-based and RHA-based geopolymer mortar. Thus, the present study is planned to investigate the specific gravity, chemical and microstructure properties, bulk density and compressive strength of the geopolymer mortars. The purpose is to demonstrate the potential use of POFA and RHA obtained locally in Sabah as binders in the production of geopolymer mortar.

\section{Materials and methods}

Both raw POFA and RHA are obtained from Beaufort and Keningau, respectively. Ordinary Portland Cement (OPC) type I was used to producing cement mortar as a control specimen in this study. Both POFA and RHA were treated via heat treatment of $500^{\circ} \mathrm{C}$ for 1.5 hours to achieve more amorphous silica and to reduce unburned carbon. Then, it was cooled at an ambient temperature of $27 \pm 1{ }^{\circ} \mathrm{C}$. The ash was sieved through a $75 \mu \mathrm{m}$ sieve before ground to 30,000 revolutions using Los Angeles Abrasion Test Machine with 12 steel bars over 16 hours. Both POFA and RHA powder are dark grey in color.

Alkaline solution used in this study was a combination of Sodium Silicate $\left(\mathrm{Na}_{2} \mathrm{SiO}_{3}\right)$ and Sodium Hydroxide $(\mathrm{NaOH})$. The concentration of $\mathrm{NaOH}$ was $8 \mathrm{M}$ and the ratio of $\mathrm{NaOH}$ and $\mathrm{Na}_{2} \mathrm{SiO}_{3}$ used was 2.5.

The standard used to determine the specific gravity, bulk density, and compressive strength are BS 1377-2:1990, BS 4551-16: 1990 and ASTM C109 correspondingly.

X-Ray Fluoride (XRF), X-Ray Diffraction (XRD), and Scanning Electron Microscope (SEM) analysis were performed at the Chemsain Sdn Bhd, Radioactive Lab Faculty of Natural Resources University Malaysia Sabah and Biotechnology Research Laboratory University Malaysia Sabah. The sample preparation for XRF and SEM are treated and grounded. Meanwhile, for the microstructure of mortar, the sample was taken from the middle of the sample.

All cement mortar samples were prepared according to ASTM C305. Meanwhile, all geopolymer mortars were prepared with ASTM C305 sand to binder ratio. The specimens were prepared with an alkaline solution to blended ash ration of 0.5 by mass. The design mix proportions are presented in Table 1 . In this study POFA based geopolymer mortar, RHA based geopolymer mortar and OPC mortars are identified as DZ-POFA, DZ-RHA, and DZ-OPC respectively.

Table 1. Mortar mix design

\begin{tabular}{|l|c|c|c|}
\hline Material & DZ-POFA & DZ-RHA & DZ-OPC \\
\hline POFA, kg & 0.5 & - & - \\
\hline RHA, kg & - & 0.5 & - \\
\hline OPC, kg & - & - & 0.5 \\
\hline Fine Aggregate, kg & 1.375 & 1.375 & 1.375 \\
\hline Alkaline solution: binder & 0.5 & 0.5 & - \\
\hline Water: cement & - & - & 0.485 \\
\hline Additional water, kg & 0.200 & 0.260 & 0.090 \\
\hline $\mathrm{NaSiO}_{3}, \mathrm{~kg}$ & 0.179 & 0.179 & - \\
\hline $\mathrm{NaOH}^{\mathrm{kg}}$ & 0.071 & 0.071 & - \\
\hline
\end{tabular}

All samples were cast in $50 \mathrm{~mm} \times 50 \mathrm{~mm} \times 50 \mathrm{~mm}$ mold and properly compacted before vibrated for $15 \mathrm{~s}$ to reduce the air voids that may have formed inside the mold. OPC-Mortar samples were cured in water curing tank after 24 hours of casting. Meanwhile, the 
geopolymer mortar samples were covered with plastic wrapping to prevent moisture loss, cured in an oven at $60^{\circ} \mathrm{C}$ for 24 hours then were kept at room temperature over a period of 7, 14, and 28 days. Figure 1 and 2 show DZ-POFA mortar and DZ-RHA mortar respectively. The color of DZ-POFA and DZ-RHA is dark grey and black respectively. The darker color produced by DZ-RHA due to higher silica content than in DZ-POFA.

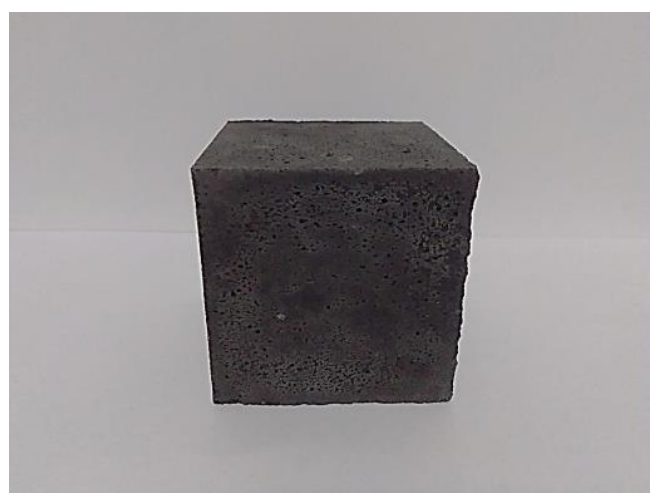

Fig. 1. DZ-POFA mortar

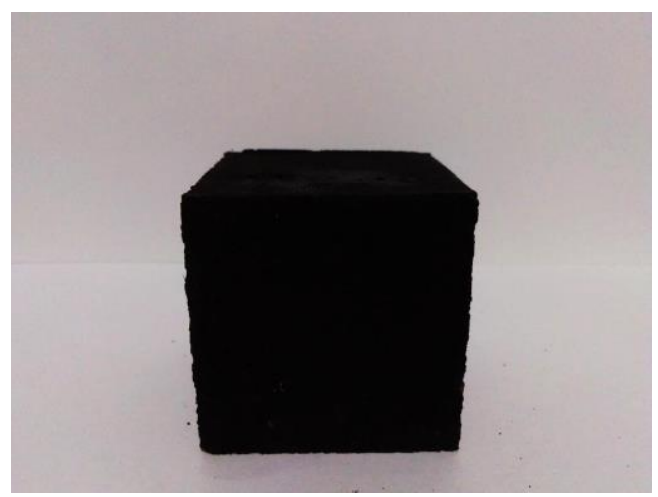

Fig. 2. DZ-RHA mortar

\section{Results and discussion}

\subsection{Characterization of POFA and RHA materials}

\subsubsection{Specific gravity}

Table 2 below shows the specific gravity (SG) of POFA, RHA, and OPC. Even though the preparation of the material is the same for both geopolymer binders, it shows that the SG of POFA is higher than SG of RHA.

Table 2. Specific gravity of POFA, RHA, and OPC

\begin{tabular}{|l|c|c|c|}
\hline Properties & POFA & RHA & OPC \\
\hline Specific gravity & 2.31 & 2.13 & 3.13 \\
\hline
\end{tabular}

\subsubsection{X-ray fluoride}

Table 3 below shows the chemical composition of POFA and RHA. Both POFA and RHA chemical composition is similar to the other research around Malaysia. Based on Table 3, POFA classifies as Class C meanwhile RHA classify as Class F pozzolanic material according to ASTM C618. 
Table 3. Chemical composition of POFA and RHA

\begin{tabular}{|c|c|c|c|c|}
\hline $\begin{array}{c}\text { Chemical } \\
\text { composition (\%) }\end{array}$ & POFA & $\begin{array}{c}\text { POFA (A. Kusbiantoro et } \\
\text { al., 2012)[7] }\end{array}$ & RHA & $\begin{array}{c}\text { RHA (M. A. Salih et } \\
\text { al., 2014)[8] }\end{array}$ \\
\hline $\mathrm{MgO}$ & 3.76 & 4.19 & 0.70 & 0.49 \\
\hline $\mathrm{Al}_{2} \mathrm{O}_{3}$ & 1.63 & 3.53 & - & 0.45 \\
\hline $\mathrm{SiO}_{2}$ & 47.44 & 47.37 & 74.13 & 89.34 \\
\hline $\mathrm{P}_{2} \mathrm{O}_{5}$ & 3.12 & 3.31 & 1.21 & 2.58 \\
\hline $\mathrm{K}_{2} \mathrm{O}$ & 15.43 & - & 10.37 & 4.98 \\
\hline $\mathrm{CaO}$ & 17.04 & 11.83 & 4.43 & 0.76 \\
\hline $\mathrm{Fe} \mathrm{O}_{3}$ & 10.02 & 6.19 & 6.98 & 0.40 \\
\hline $\mathrm{Si} / \mathrm{Al}$ ratio & 29.10 & - & 74.13 & - \\
\hline
\end{tabular}

\subsubsection{X-ray diffraction}

The XRD pattern of POFA powder and RHA powder are shown in Figure 4 and 5 respectively. Both figures show an amorphous hump (as indicated in the circle) in the XRD pattern which indicates the presence of amorphous silica in both POFA and RHA. Previous studies have reported that the amorphous silica has an important role in the pozzolanic activity $[5,9,10,11]$. Meanwhile, the peak illustrated in the figures indicates the presence of crystalline in the binder. They only act as void filler and do not participate in the pozzolanic activity $[5,9,10,11]$.

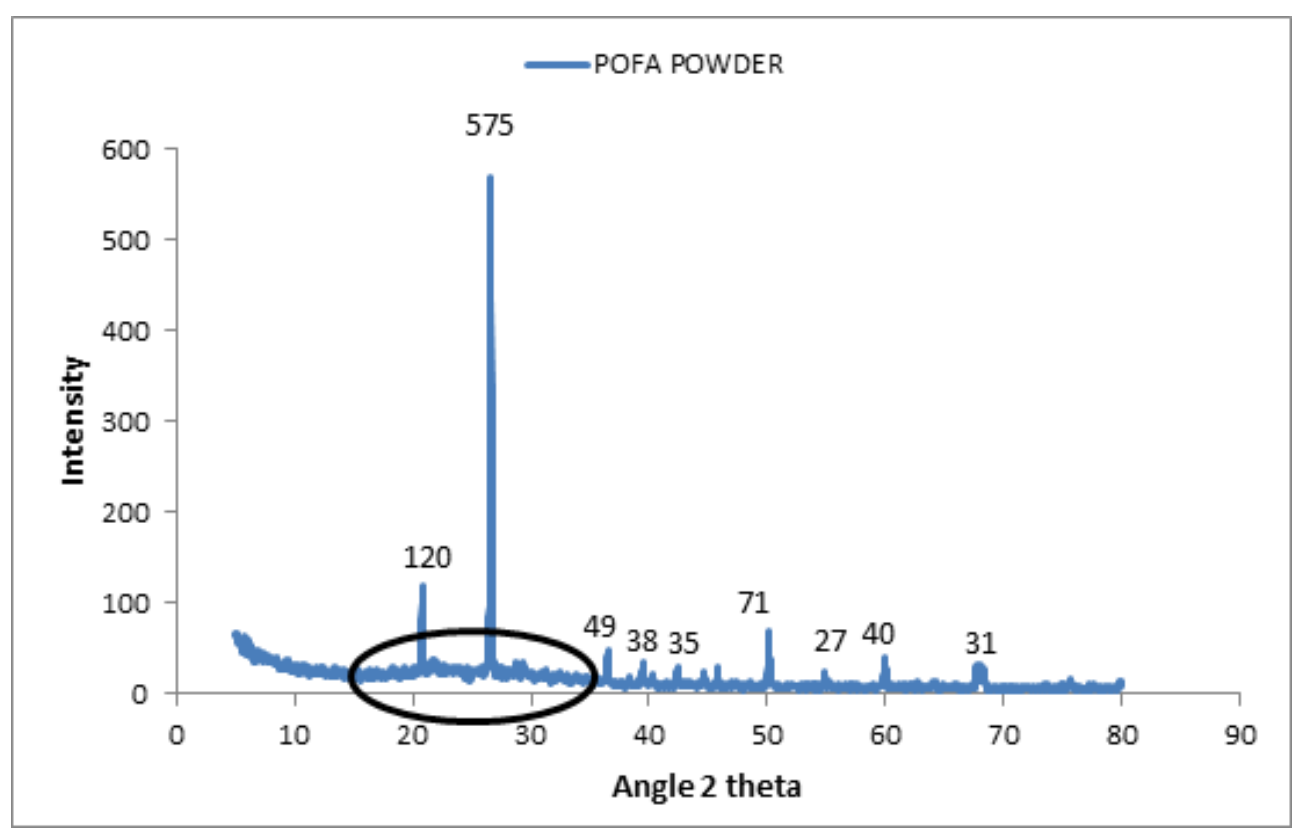

Fig. 4. XRD pattern of POFA powder 


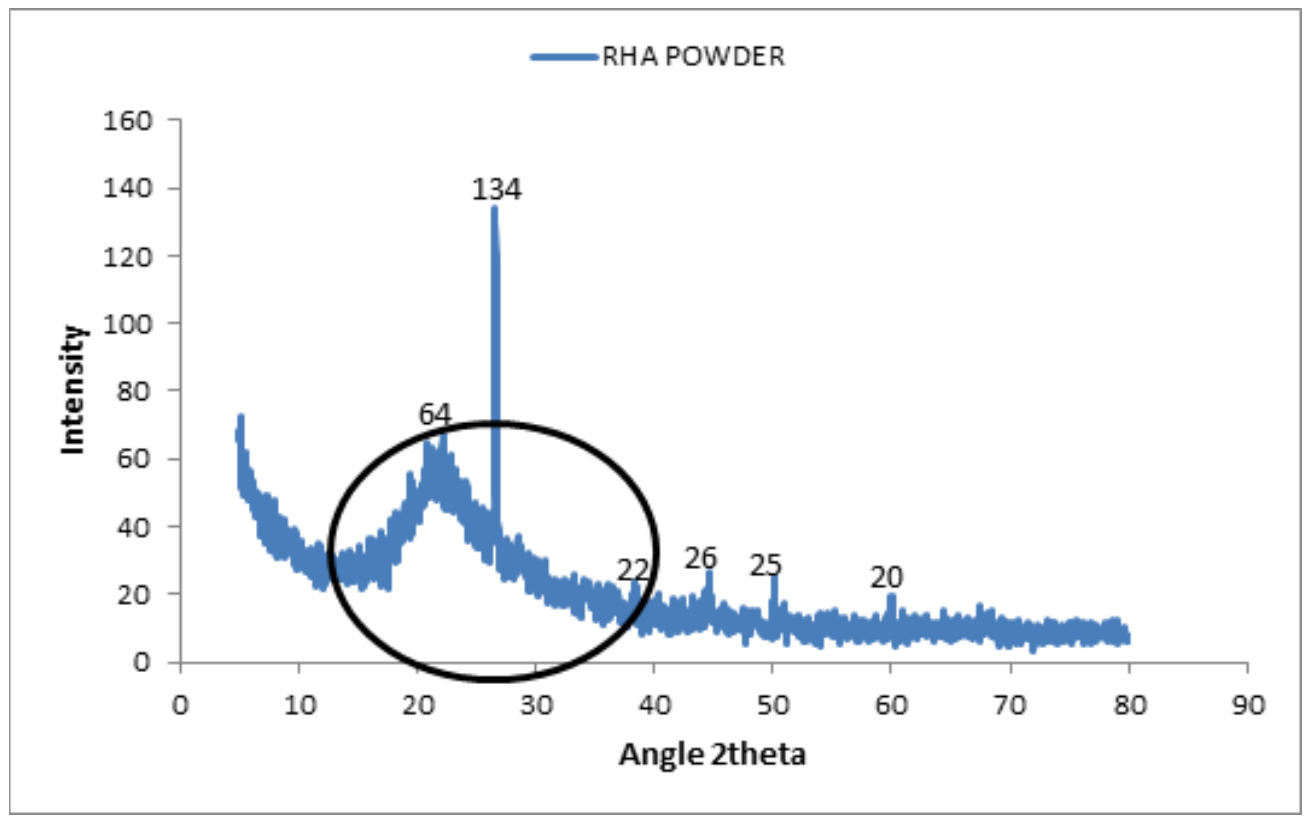

Fig. 5. XRD pattern of RHA powder

\subsubsection{Scanning electron microscope}

The particle morphology of POFA and RHA powder using SEM are presented in Figure 6 and 7 respectively. As shown in the figures, both POFA and RHA consist of very irregular shaped particles. Although the preparation of both materials is the same, most of the RHA particles are bigger than the POFA particles thus producing lower specific gravity than POFA.

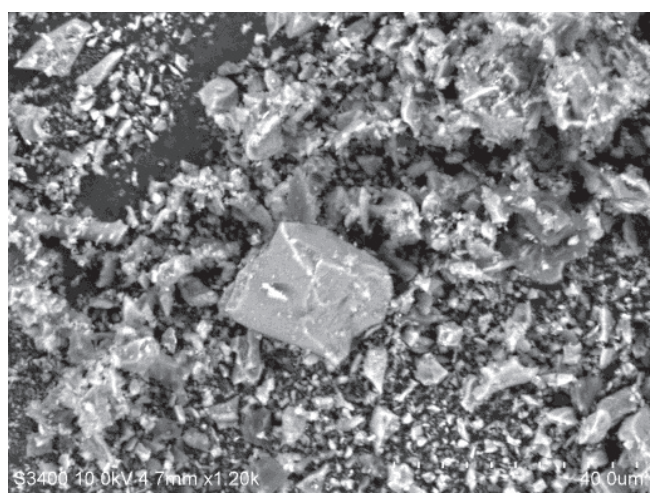

Fig. 6. SEM of POFA powder

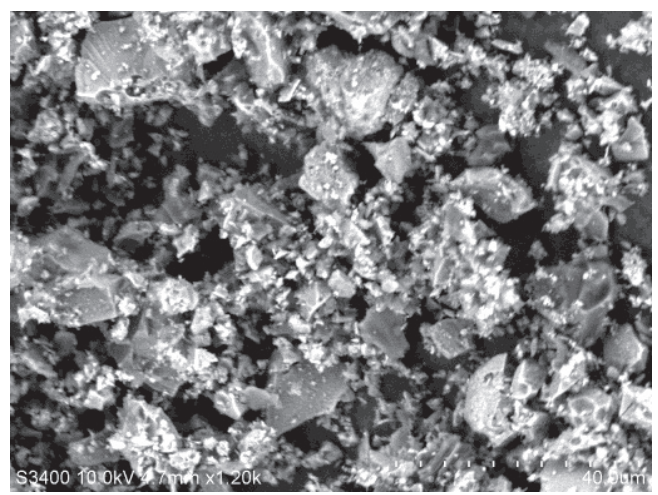

Fig. 7. SEM of RHA powder 


\subsection{Microstructure of POFA-based geopolymer mortar and RHA-based geopolymer mortar}

\subsubsection{X-ray diffraction}

Figure 8 and 9 show the XRD pattern for POFA and RHA mortar respectively. As shown in the figures, there are no new peaks appeared in any geopolymer samples compare to the XRD pattern of the parent materials (as shown in Figure 4 and 5). However, these peaks increase in intensity. This indicates that the parent materials were dissolved into the inorganic polymeric materials [12].

\subsubsection{Scanning Electron Microscope}

Figure 10, 11 and 12 show the morphology of the DZ-Cement, DZ-POFA, and DZ-RHA respectively. All samples were extracted from the mid-section of the sample.

Based on the figures, visible cracks are observed on both DZ-POFA and DZ-RHA while no cracks are observed in DZ-Cement. It shows that the DZ-cement has the densest structure followed by DZ-POFA and DZ-RHA. This indicates that some of the pozzolanic reactions in POFA and RHA did not take place. This is because the amount of water needed in DZ-POFA and DZ-RHA are higher due to the surface area of the POFA and RHA particles [11], which lead to higher solid-to-liquid ratio thus more voids or cracks are formed [13].

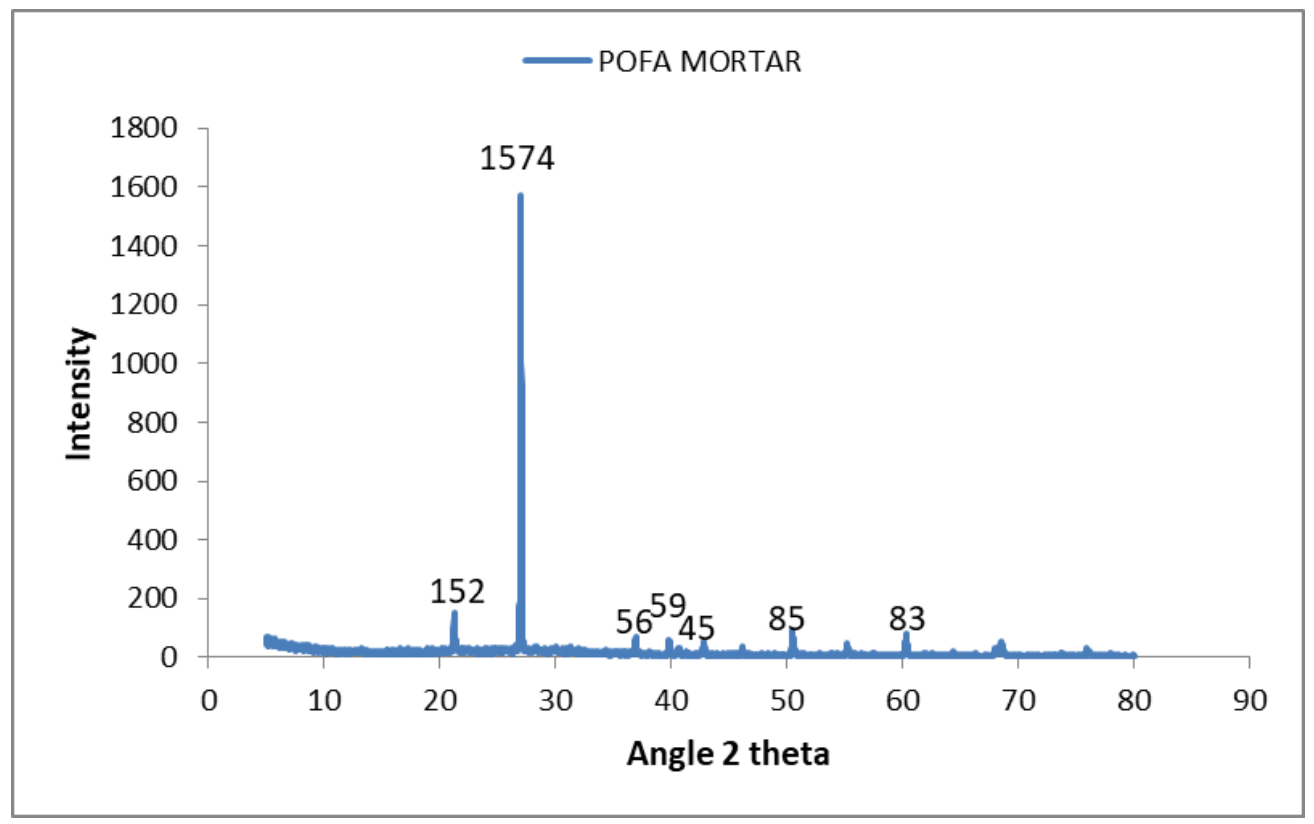

Fig. 8. XRD pattern of POFA mortar 


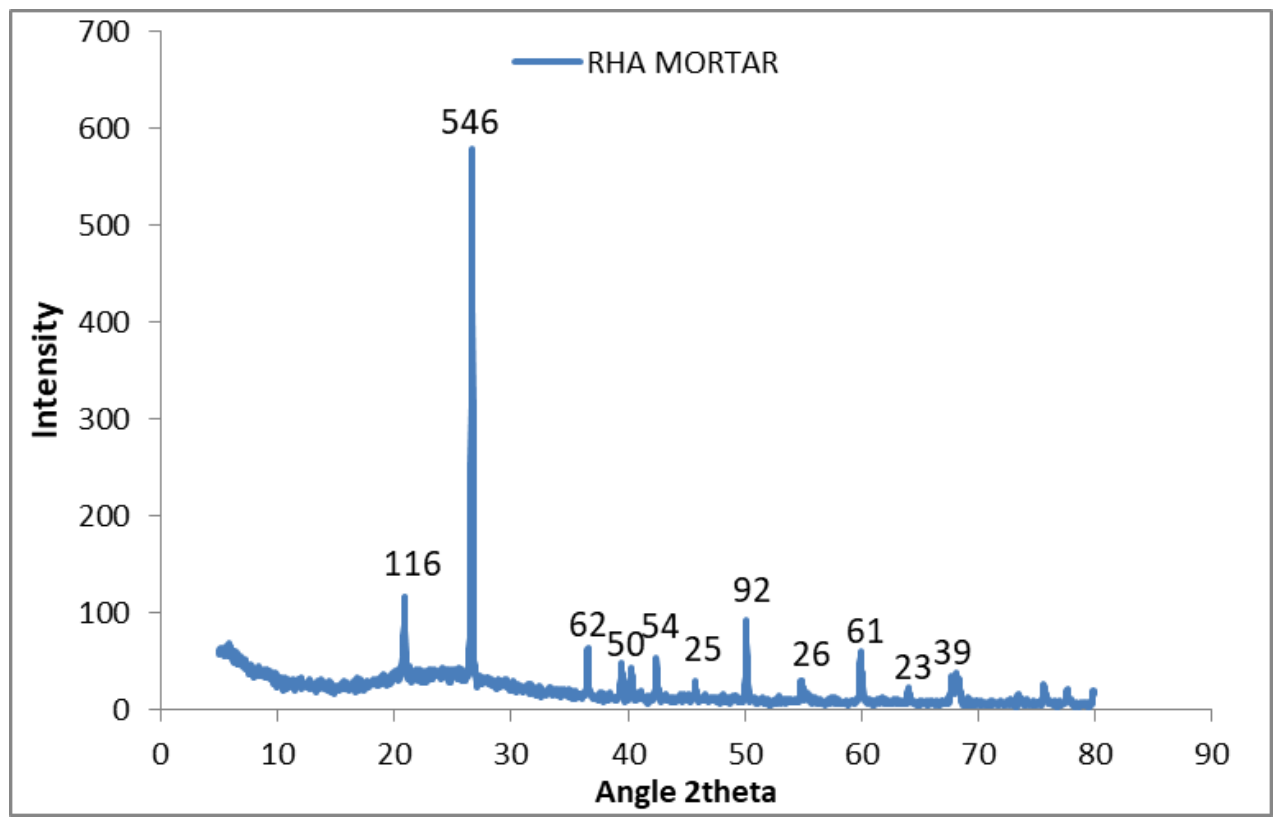

Fig. 9. XRD pattern of RHA mortar

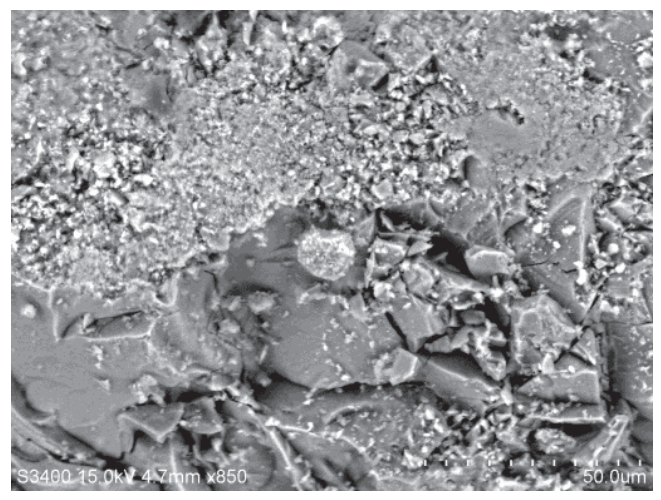

Fig. 10. SEM of OPC mortar

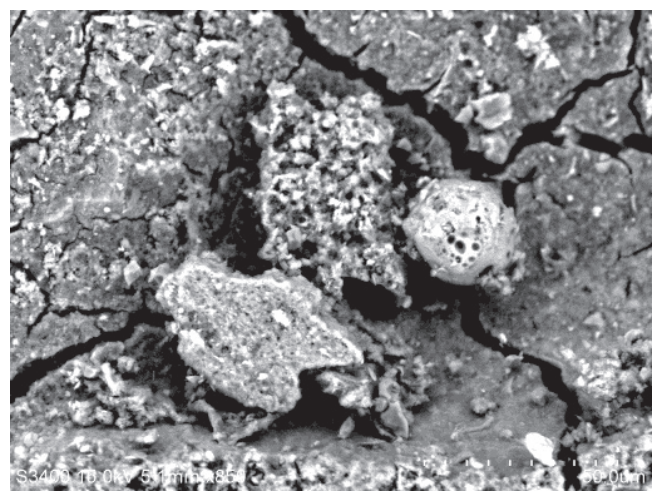

Fig. 11. SEM of POFA based geopolymer mortar 


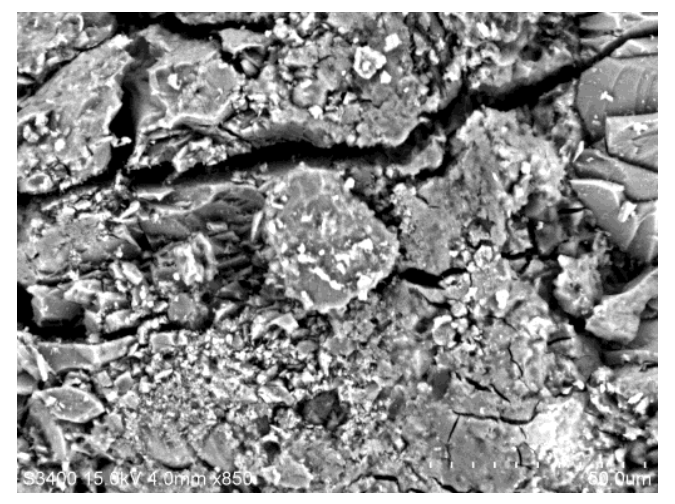

Fig. 12. SEM of RHA based geopolymer mortar

\subsection{Bulk density and compressive strength of OPC mortar and POFA-based geopolymer mortar and RHA-based geopolymer mortar.}

\subsubsection{Bulk Density}

Table 4 shows the bulk density of DZ-Cement, DZ-POFA and DZ-RHA specimens at $28^{\text {th }}$ curing days. The result shows that the bulk density of the DZ-Cement is the highest followed by DZ-POFA and DZ-RHA. These results agree well with the SEM data where DZ-Cement shows the densest structure and the specific gravity as shown in table 2 .

Table 4. Bulk density of specimens at $28^{\text {th }}$ curing days

\begin{tabular}{|l|c|c|c|}
\hline Specimen & DZ-Cement & DZ-POFA & DZ-RHA \\
\hline Bulk density, $\mathrm{kg} / \mathrm{m}^{3}$ & 2083.2 & 1967.8 & 1812.8 \\
\hline
\end{tabular}

\subsubsection{Compressive Strength}

Figure 13 shows the compressive strength of DZ-Cement, DZ-POFA, and DZ-RHA at 7th, 14th, and 28th curing days. It shows that the compressive strength of all the mortars increases as the curing day increases with the DZ-Cement as the mortar with the highest compressive strength, followed by DZ-RHA and DZ-POFA. This indicates the progressive of C-S-H gel formation in the OPC mortar and the polymerization in the geopolymer mortar [9]. 


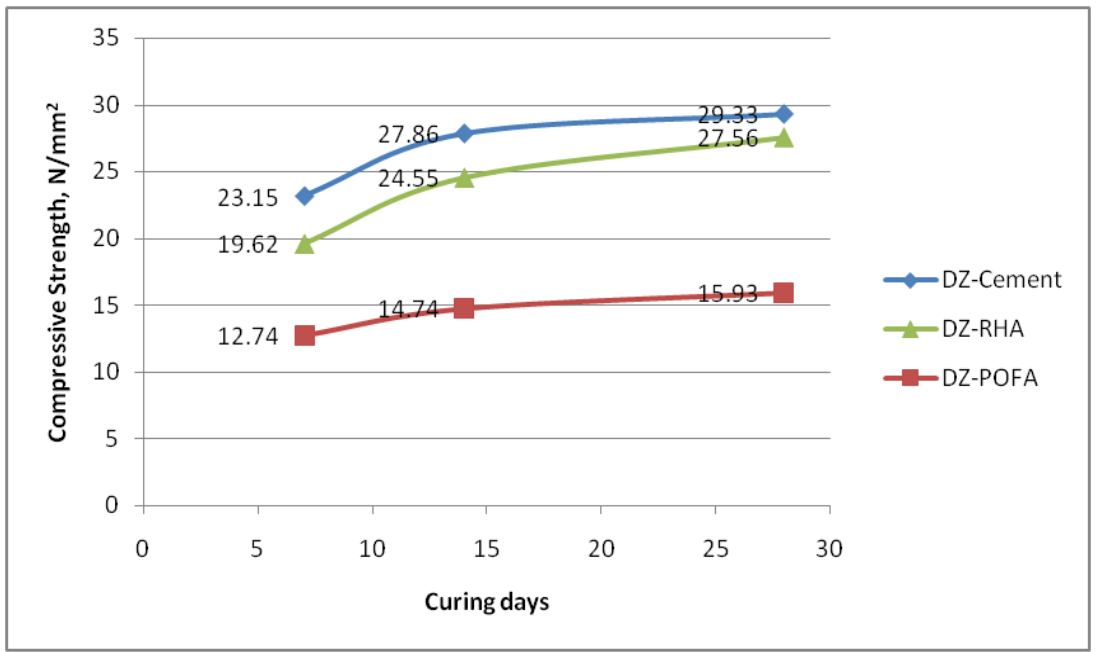

Fig. 13. Compressive strength of DZ-Cement, DZ-POFA, and DZ-RHA

As can be seen in Figure 14, the compressive strength development rate of DZ-POFA at $7^{\text {th }}$ days of curing is higher than DZ-RHA. However at $14^{\text {th }}$ days of curing the compressive strength development rate of DZ-POFA and DZ-RHA are the same. The higher early strength development in DZ-POFA than DZ-RHA is due to the low $\mathrm{Si} / \mathrm{Al}$ ratio in POFA which is 29.10 (as shown in Table 3), hence a high amount of Al component. The Al component dissolved easier than Si components at an early stage of geo-polymerisation. This contributes to the strength development rate at the early stage [11].

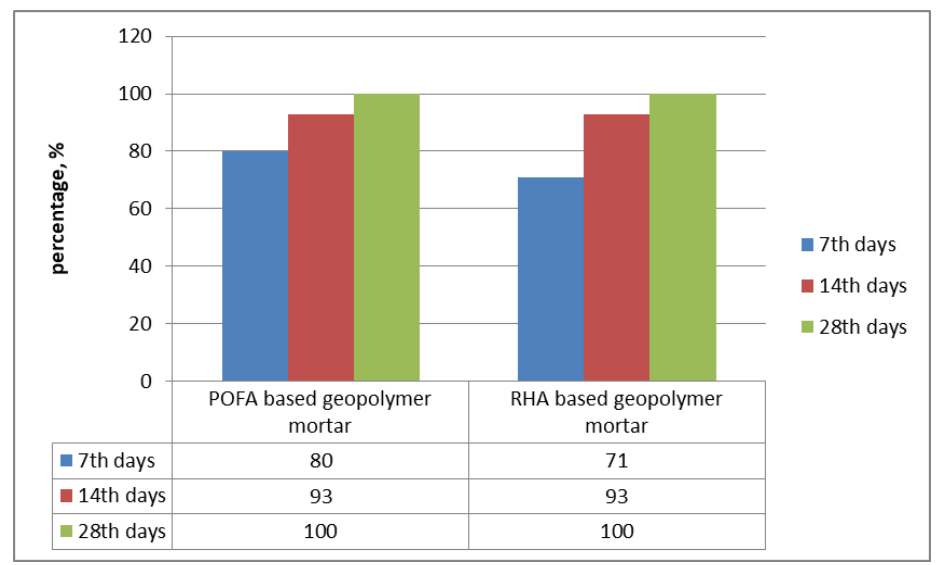

Fig. 14. Compressive strength development rate of POFA based and RHA based geopolymer, \%

\subsubsection{Correlation between bulk density and compressive strength}

Generally, the compressive strength of mortar increases with a rising of bulk density [11]. This agrees well with the DZ-Cement with the highest bulk density and the compressive strength as depicted in Figure 15. This is because the amount of addition of alkaline solution and water required for the geopolymer mortars to form homogeneity and increases the workability of the mortars are higher than the amount of water required for OPC 
mortars, hence contributing to the lower compressive strength compare to the DZ-Cement [10] and also due to lower specific gravity of the material.

Meanwhile, for geopolymer mortars, despite higher bulk density in DZ-POFA, it was observed that its compressive strength is lower than DZ-RHA. This is due to the high silica content in RHA that promotes more silica-oxygen-silica ( $\mathrm{Si}-\mathrm{O}-\mathrm{Si}$ ) bonds than POFA. According to Mijarash et al. [9], the bond is stronger than silica-oxygen-alumina ( $\mathrm{Si}-\mathrm{O}-\mathrm{Al}$ ) and alumina-oxygen-alumina (Al-O-Al) bonds which greatly contribute to the higher compressive strength in DZ-RHA.

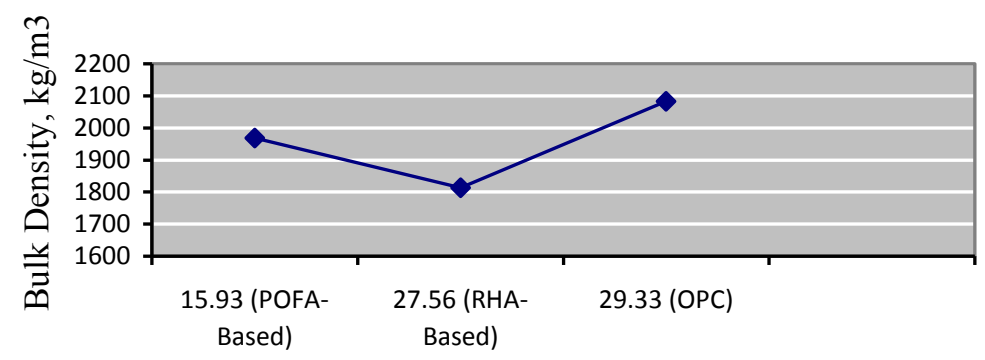

Compressive Strength, MPa

Fig. 15. Correlation between bulk density and compressive strength

\section{Conclusion}

In this study, POFA-based and RHA-based geopolymer mortars were prepared. In addition to the specific gravity and bulk density, the tests included are the microstructural analysis of XRF, XRD, and SEM. The compressive strength of the mortars was investigated for $7^{\text {th }}$, $14^{\text {th }}$, and $28^{\text {th }}$ days. Based on the results obtained, the following conclusion is drawn:

1. Both POFA and RHA materials fulfilled the ASTM C618 criteria to be classified as pozzolanic material.

2. The bulk density for the OPC mortar is the highest followed by the POFA-based and RHA-based geopolymer mortars. This is because the amount of addition of alkaline solution and water required for the geopolymer mortars to form homogeneity is higher than the amount of water required for OPC mortars and lower specific gravity of the material.

3. Meanwhile, highest compressive strength was observed in OPC mortar followed by the RHA-based and POFA-based geopolymer mortar. This is due to the high silica content in RHA and POFA, which increases the water absorption thus reduces the compressive strength of the geopolymer mortars.

4. Due to the high silica content in RHA, the compressive strength of RHA-based geopolymer mortar is higher than the POFA-based geopolymer mortar.

The authors would like to express their gratitude to the Universiti Malaysia Sabah for funding the research project under Skim Geran Penyelidikan UMS (Skim Pensyarah Lantikan Baru). 


\section{References}

1. Z. Yahya, R. A. Razak, M. M. A. B. Abdullah, M. A. A. Rahim, A. Nasri. Rice husk (RH) as additive in fly ash based geopolymer mortar. AIP Conference Proceedings, 1885 (2017).

2. B. Bakhtyar, T. Kacemi, A. Nawaz. A Review on Carbon Emissions in Malaysia Cement Industry, 7(3), 282-286 (2017).

3. P. H. R. Borges, V. A. Nunes, T. H. Panzera, G. Schileo, A. Feteira. The Influence of Rice Husk Ash Addition on the Properties of Metakaolin-Based Geopolymers. The Open Construction and Building Technology Journal, 10, 406-417 (2016).

4. J. B. M. Dassekpo, X. Zha, J. Zhan, J. Ning. The effects of the sequential addition of synthesis parameters on the performance of alkali activated fly ash mortar. Results in Physics, 7, 1506-1512. (2017).

5. N. M. Altwair, M. A. M. Johari, S. F. S. Hashim, A. M. Zeyad. Mechanical Properties of Engineered Cementitious Composite with Palm Oil Fuel Ash as a Supplementary Binder. Advanced Materials Research, 626, 121-125 (2012).

6. M. Muttashar, W. Lokuge, W. Karunasena. Geopolymer Concrete: The Green Alternative with Suitable Structural Properties. 23rd Australasian Conference on the Mechanics of Structures and Materials (ACMSM23), 1, 101-106 (2014).

7. A. Kusbiantoro, M. F. Nuruddin, N. Shafiq, S. A. Qazi. The effect of microwave incinerated rice husk ash on the compressive and bond strength of fly ash based geopolymer concrete. Construction and Building Material, 36, 695-703 (2012).

8. M. A. Salih, A. A. A. Ali, N. Farzadnia. Characterization of mechanical and microstructural properties of palm oil fuel ash geopolymer cement paste. Construction and Building Material, 65, 592-603 (2014).

9. M. J. A. Mijarsh, M. A. M. Johari, Z. A. Ahmad. Synthesis of geopolymer from large amounts of treated palm oil fuel ash: Application of the Taguchi method in investigating the main parameters affecting compressive strength. Construction and Building Materials, 52, 473-481 (2014).

10. S. V. Patankar, S. S. Jamkar, Y. M. Ghugal. Effect of Water-To-Geopolymer Binder Ratio on the Production of Fly Ash Based Geopolymer Concrete. International Journal of Advanced Technology in Civil Engineering, 1, 79-83 (2013).

11. N. Ranjbar, M. Mehrali, U. J. Alengaram, H. S. C. Metselaar, M. Z. Jumaat. Compressive strength and microstructural analysis of fly ash/palm oil fuel ash based geopolymer mortar under elevated temperatures. Construction and Building Materials, 65, 114-121 (2014).

12. C. L. Hwang, T. P. Huynh. Effect of alkali-activator and rice husk ash content on strength development of fly ash and residual rice husk ash-based geopolymers. Construction and Building Materials, 101, 1-9. (2015).

13. D. L. Kong, J. G. Sanjayan, K. Sagoe-Crentsil. Comparative performance of geopolymers made with metakaolin and fly ash after exposure to elevated temperatures. CemConcr 37(12):1583-9. (2007). 